\title{
Evaluation of the Main Macroeconomic Indicators and Their Role in the Economic Growth of Albania
}

\author{
Ph.D., Eriona Deda \\ Assistant Professor, Bexhet Brajshori \\ Assistant Professor, Drita Krasniqi \\ Assoc. Prof., Edmond Kadiu
}

Doi:10.5901/ajis.2016.v5n3s1p482

\section{Abstract}

This project it is focused in the link between some macroeconomic indicators as an important factor of sustainable growth and the development economy. Specifically in this study is given a presentation of inflation on years in our country, giving the factors that have influenced in it. Also we have received some data from government statistics: Dependence of the nominal stated interest rate on loans from, which used to measurement of (GDP) Gross Domestic Product. Potential product measured using the linear regression method. The results of the methods were compared using time series analysis, for measurement of economy cycles and their intensity. Economic stability is a necessary condition for sustained economic growth of a country and for improving its welfare in the long term. It is also evidenced by the experience of different countries. As the experience as well as theory have shown that the establishment and maintenance of equilibrium within and between sectors of the economy is a necessary condition of economic growth.

Keywords: Inflation, economic growth, GDP - Gross Domestic Product, CPI- Price Index consumer

\section{Introduction}

Specifically this study gives a presentation on inflation rates by years in Albania and the factors that influenced it. Also, data from government statistics such as dependence of the nominal stated interest rate on loans from the consumer price index are used to measure inflation and measurement of (GDP) Gross Domestic Product. Here they emerge to model the variables which consumers.

The CPI one of indicators which is used to measure inflation.

Gross domestic product

The data are for the period Q1 1995 -T2: 2011 taken by the Ministry of Finance, statistical INSTAT ect..

The Econometric program that is used is EViews7 and the variables we have noticed:

1. The nominal interest-rate loans

2. CPI- Price Index consumer, which serves to measure inflation

3. GDP level of Gross Domestic Product

The model that we will present below is the Bank of Albania's efforts to modeling one of this.

\subsection{General Issues}

In our study we have analysed the relationship between GDP inflation - interest and their role in the economic growth for the Albania's case.

Also this study have analyzed some econometric models, to see the connection that exists between variables, and also to test the statistical significance of the models.

\section{Material and Methods}

In this study we have received some data from government statistics: dependence of the nominal stated interest rate on loans from, which used to measurement of (GDP) Gross Domestic Product. 
The Econometric program that was used was EViews7 and the variables we have noticed: The data are for the period Q1 1995 -T2: 2011 taken by the Ministry of Finance, Statistical , INSTAT.

Statistical Reports of the Ministry of Finance. Publications by Instad, some topic by "Econometrics" module, some topic by "Money and financial institutions module" ect..

\section{Testing the Model with Durbin-Watson Test}

Durbin-Watson test that is more useful test for detecting the serial correlation known as autocorrelation. Durbin-Watson test moves from $(0,4)$. To perform the test, we build hypotheses:

HO: $p=0$ (no autokorelacion)

Ha: $\hat{\rho} \neq 0$ (no autokorelacion)

Durbin-Watson stat in the value 1.018 testifies to the value of the non-existence of autocorrelation (we know that DW2 $=2$ or near 2, the base hypotheses is $\mathrm{HO}: \mathrm{p}=0$ that means not has autokorelacion).

Assessment of simple linear relationship between interest rates and gross domestic produktitit

Dependent Variable: I

Method: Least Squares

Date: 11/19/12 Time: 13:06

Sample: 19952011

Included observations: 17

\begin{tabular}{|c|c|c|c|c|}
\hline Variable & Coefficient & Std. Error & t-Statistic & Prob. \\
\hline C & 31.01934 & 4.066870 & 7.627325 & 0.0000 \\
\hline GDP & -0.017542 & 0.005125 & -3.422996 & 0.0038 \\
\hline R-squared & 0.438558 & \multicolumn{2}{|c|}{ Mean dependent var } & 18.25882 \\
\hline Adjusted R-squared & 0.401128 & \multicolumn{2}{|c|}{ S.D. dependent var } & 8.660691 \\
\hline S.E. of regression & 6.702233 & \multicolumn{2}{|c|}{ Akaike info criterion } & 6.752890 \\
\hline Sum squared resid & 673.7989 & \multicolumn{2}{|c|}{ Schëarz criterion } & 6.850915 \\
\hline Log likelihood & -55.39956 & \multicolumn{2}{|c|}{ Hannan-Quinn criter. } & 6.762633 \\
\hline F-statistic & 11.71690 & \multicolumn{2}{|c|}{ Durbin-Ëatson stat } & 1.177222 \\
\hline Prob(F-statistic) & 0.003775 & & & \\
\hline
\end{tabular}

The bond that exists between these two variables is expressed by the equation

$\mathrm{I}=31.019-0.0175$ * GDP

We now do the simple linear interpretation:

If GDP increases by one unit then the interest rate will decrease by 0.0175 points.

If $\mathrm{GDP}$ is 0 then the interest rate is 31,019

The coefficient of determination R2 (R-squared) is calculated by formula

$R^{2}=\frac{S K R}{S K T}=1-\frac{S K G}{S K T}=1-\frac{\sum u_{i}^{2}}{\sum y_{i}^{2}}$

And it shows us the percentage of dependence variance variable NPL / TKB explained by all the variables together. But in our case we have ready from the table of regression the value of 0.438 . So $44 \%$ of the interest rate variance explained by GDP and $56 \%$ is explained by other variables not included in the model.

we do the test to show how important is model

Ho: $\beta 2=0 \quad$ (the model isn't important)

Ha: $\beta 2 \neq 0 \quad$ (the model is important)

We choose the Student test. We know that:

$t_{v}=\frac{\beta_{i}}{\operatorname{se}\left(\beta_{i}\right)} \sim t_{\frac{\alpha}{2}, n-k}$

From the table of regression we can see that $\left|t_{v}\right|=|-3.42|>t_{k=1.96} \rightarrow H_{0} \downarrow$

In this case we say that the basic hypothesis falls down and our model is statistically significant. since we are in the two variable model to the same conclusion we will come and if we analyze the table ANOVA and Fisher criteria where if $\mathrm{Fv}>\mathrm{Fk}$ then we say that the basic hypothesis is rejected ( $\mathrm{HO} \downarrow)$ and accept the alternative hypothesis ( $\mathrm{Ha} \uparrow)$ that model 
is statistically significant.

The opposite if $\mathrm{Fv}<\mathrm{Fk}$ which means that the model is not statistically significant $\mathrm{Ho} \uparrow$.

In our case we can see that $\mathrm{Fv}=11.71>\mathrm{F}_{\mathrm{k}}=5$ which means that $\mathrm{Ho} \downarrow$ and our model is statistically significant.

Durbin-Watson stat in the value 1.177 testifies to the value of the non-existence of autocorrelation (we know that DW2 $=2$ or near 2 , the base hypotheses is $\mathrm{HO}: \mathrm{p}=0$ that means not has autokorelacion).

\section{The Multiple Model of Regression}

The model in which the number of explanatory variables is greater than regression model. Let's see what happens if we include all independent variables on the model in simultaneously.

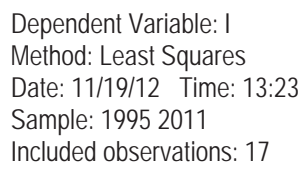

\begin{tabular}{|c|c|c|c|c|}
\hline Variable & Coefficient & Std. Error & t-Statistic & Prob. \\
\hline C & 21.59212 & 3.194620 & 6.758901 & 0.0000 \\
\hline ICK & 0.573860 & 0.116943 & 4.907178 & 0.0002 \\
\hline GDP & -0.009464 & 0.003613 & -2.619365 & 0.0202 \\
\hline R-squared & 0.793589 & \multicolumn{2}{|c|}{ Mean dependent var } & 18.25882 \\
\hline Adjusted R-squared & 0.764102 & \multicolumn{2}{|c|}{ S.D. dependent var } & 8.660691 \\
\hline S.E. of regression & 4.206437 & \multicolumn{2}{|c|}{ Akaike info criterion } & 5.869894 \\
\hline Sum squared resid & 247.7176 & \multicolumn{2}{|c|}{ Schëarz criterion } & 6.016932 \\
\hline Log likelihood & -46.89410 & \multicolumn{2}{|c|}{ Hannan-Quinn criter. } & 5.884510 \\
\hline F-statistic & 26.91300 & \multirow{2}{*}{\multicolumn{2}{|c|}{ Durbin-Watson stat }} & 1.219809 \\
\hline Prob(F-statistic) & 0.000016 & & & \\
\hline
\end{tabular}

The relation that exists between the variables is given by the following equation:

$\mathrm{I}=21.592+0.5738^{*} \mathrm{ICK}-0.0094^{*} \mathrm{GDP}$

If $\mathrm{CPI}$ increase by one unit and the others variables independently are constant ,then the interest rate will increase by 0.5738 units

If GDP increases by one unit and the others variables independently are constant, then the interest rate will decrease by 0.0094 points.

If all independently variables are 0 then the interest rate is 21.592

Let do the Interpretation of multiple regression model increase.

If in the model we do increase the number of explanatory variables, the coefficient of determination R2 will only

This is because with the increasing number of explanatory variables, the error will be reduced, since the sum of the squares errors (SKG) decreases. The fact that SKT = SKR + SKG, when amount of the squared errors decreases, the amount of squares regression will increase and consequently the coefficient of determination R2 will increase.

In the case of multiple regression model it is necessary to correct the determination coefficient to eliminate the overvaluation and therefore is used the corrected determination coefficient which is obtained by dividing the amount of squares regression with the degrees of freedom .

Then in our case the corrected coefficient of determination is 0.76 , which means that $76 \%$ of the variance explained by inflation and GDP and $24 \%$ of the variance explained of other variables that are not included in the model.

From this higher percent $\%$ of this coefficient expect our model to be statistically significant.

We do the test to show how important is model

We will do testing with Fischer, seeing that $\mathrm{Fv}=26.91>\mathrm{Fk}=5$ means that $\mathrm{Ho} \downarrow$ and our model is statistically significant , based on the highest percent of adjusted determination coefficient.

We do the test of statistical significance of partial coefficients regression.

With the help of Fisher criterion we conclude that whether or not the connection between variables was important. Namely that at least one of the parameters was different from zero, then it is interesting to carry out a new test to 
evaluate the parameters that are important, but always knowing that the remains variables have normal distribution $u_{i} \sim N\left(0, \sigma^{2}\right)$.

We build hypotheses:

$\beta 2$ - Consumer Price Index, independent variable

Ho: $\beta 2=0$ isn't important

$\mathrm{Ha}: \beta 2 \neq 0$ is important

The null hypothesis will be rejected if $\left|\mathrm{t}_{\mathrm{v}}\right|>\mathrm{t}_{\mathrm{k}} \mathrm{ku} \quad t_{\mathrm{v}}=\frac{\beta_{i}}{\operatorname{se}\left(\beta_{i}\right)} \sim t_{\frac{\alpha}{2}, n-k}$ where in our case

TV $=5.907>\mathrm{tk}=1.96$ that brings us to the basic hypothesis is rejected. This means that the partial coefficient of regression $\beta 2$ Consumer Price Index is statistically significant.

$\beta 3$-Gross Domestic Product, independent variable

Ho: $\beta 3=0$ isn`t important

$\mathrm{Ha}: \beta 3 \neq 0$ is important

In our case $|-2.619|$ tv $\Rightarrow$ that $t k=1.96$, The null hypothesis will be rejected means that $\beta 3$ the partial coefficient at GDP is statistically significant.

We conclude that: Since all partial regression multiple coefficients are statistically significant, after testing of their statistical significance then we say that our model is better.

\section{Wald Test}

Let do the testing of equality of two partial coefficients of model.

We are doing the testing the hypothesis if that $\beta 2$ and $\beta 3$ are equal.

Prepare the assumptions:

Ho: $\beta 2=\beta 3$ ose $\beta 2-\beta 3=0$

Ha: $\beta 2 \neq \beta 3$ ose $\beta 2-\beta 3 \neq 0$

Wald Test:

Equation: EQ03

\begin{tabular}{llll}
\hline \hline Test Statistic & Value & Df & Probability \\
\hline \hline & & & \\
t-statistic & 5.057359 & 14 & 0.0002 \\
F-statistic & 25.57688 & $(1,14)$ & 0.0002 \\
Chi-square & 25.57688 & 1 & 0.0000 \\
\hline \hline Null Hypothesis: C(2)=C(3) & & \\
Null Hypothesis Summary: & & \\
\hline \hline Normalized Restriction $(=0)$ & Value & Std. Err. \\
\hline \hline $\mathrm{C}(2)-\mathrm{C}(3)$ & 0.583325 & 0.115342 \\
\hline \hline
\end{tabular}

Restrictions are linear in coefficients.

For testing the hypothesis will use student test:

In this case we see from the table that TV $=5,057>t k=1.96$, then the null hypothesis is rejected and thus mean that the partial coefficients $\beta 2$ and $\beta 3$ are not equal.

\section{Results and Discussions}

In this study we have analysed the relationship between both real and nominal interest rate. In our study we have analyzed some econometric models, to see the connection that exists between variables. Also we have analysed the multiple regression. From result our model was statistically significant. 


\section{Conclusions}

In this study we we test the model with Durbin-Watson test.

Durbin-Watson is a test statistic used to detect the presence of autocorrelation (a relationship between values separated from each other by a given time lag) in the residuals (prediction errors) from a regression analysis. The result of Durbin-Watson test in our case was that not has autokorelacion.

In the case of multiple regression model it is necessary to correct the determination coefficient to eliminate the overvaluation and therefore is used the corrected determination coefficient which is obtained by dividing the amount of squares regression with the degrees of freedom.

From result our model was statistically significant.

In the social and natural sciences multiple regression procedures are very widely used in research. In general, multiple regression allows the researcher to ask (and hopefully answer) the general question "what is the best predictor of ...".

We used Wald Test, to test the equality of two partial coefficients of model.the Wald test in the context of logistic regression is used to determine whether a certain predictor variable $\mathrm{X}$ is significant or not. It rejects the null hypothesis of the corresponding coefficient being zero. The test consists of dividing the value of the coefficient by standard error $\sigma$. The Wald test can be used to test the true value of the parameter based on the sample estimate. In our case we test the model with the student test, and from the result the null hypothesis was rejected and thus mean that the partial coefficients $\beta 2$ and $\beta 3$ were not equal.

\section{References}

Osmani. M, Econometric Module, Agricultural University of Tirana ,Albania 2002

Osmani. M, Econometric Module, Agricultural University of Tirana, The regression models one factorial, page 15, 20 ,Albania 2002

Osmani. M, Econometric Module, Agricultural University of Tirana, The correlation coefficient and determination, page 27 , Albania 2002

Osmani. M, Econometric Module, Agricultural University of Tirana ,The multiple model of regression, page 49,Albania 2002

Osmani. M, Econometric Module, Agricultural University of Tirana, calculation of R² and R, page 54,Albania 2002

Osmani. M, Econometric Module, Agricultural University of Tirana, the hypotheses on partial regression coefficients, page 57,Albania 2002.

Osmani. M, Econometric Module, Agricultural University of Tirana, The general hypothesis about the importance of regression, page 58, Albania 2002.

Osmani. M, Econometric Module, Agricultural University of Tirana, the dynamic econometric models, autocorrelation, page 99, Albania 2002.

Haavelmo, T. (1943), Statistical implications of a system of simultaneous equations, Econometrica 11, 1-12.

D. Salko, O. Dhuci, Money and financial institutions, Publication from the University of Tirana, Albania 2010.

M. Osmani, Methods of econometrics Module, Agricultural University of Tirana, Albania 2005

Statistical Reports of the Bank of Albania Annual Reports of the Bank of Albania, Inflation And Prices, file:///C:/Users/user/Downloads/Raporti_Vjetor_1995.pdf 